\title{
Tutores sobresalientes y sus prácticas de tutoría académica en una universidad mexicana
}

\author{
Elizabeth Ocampo-Gómez ${ }^{\star *}$, Nereida Rodríguez-Orozco ${ }^{2}$ y Manuel F. Aguilar-Tamayo ${ }^{3}$ \\ (1) Instituto de Investigaciones en Educación, Universidad Veracruzana. Lomas del Estadio s/n. CP. 91000. Xalapa, \\ Veracruz, México (correo-e: eocampo@uv.mx) \\ (2) Facultad de Ciencias Agrícolas, Universidad Veracruzana. Lomas del Estadio s/n. CP. 91000. Xalapa, Veracruz, \\ México (correo-e: nrodriguez@uv.mx) \\ (3) Instituto de Ciencias de la Educación, Universidad Autónoma del Estado de Morelos. Avenida Universidad 1001, \\ Chamilpa, 62209 Cuernavaca, Morelos, México (correo-e: manuel.aguilart@uaem.edu.mx)
}

* Autor a quien debe ir dirigida la correspondencia.

Recibido Feb. 17, 2021; Aceptado Abr. 15, 2021; Versión final May. 20, 2021, Publicado Ago. 2021

\begin{abstract}
Resumen
Este estudio se enfoca en describir la práctica tutorial de un grupo de profesores con altos puntajes en su desempeño como tutores y en determinar si estas prácticas son buenas prácticas para su sistematización y difusión. Mediante un diseño cualitativo, se realizaron ocho grupos focales que registraron las narrativas de 23 tutores y 16 estudiantes. Se analizan las transcripciones mediante métodos de codificación para conocer sus representaciones sobre la tutoría, las formas de organización, la comunicación y las condiciones en que se realizan las interacciones tutoriales. Los resultados muestran que algunas de las acciones de tutores y tutorados se desarrollan en tiempos y espacios distintos a los considerados en la normativa y prácticas de gestión de la institución y suponen riesgos profesionales y personales por la falta de estrategias y soportes institucionales. Se concluye que a pesar del alto compromiso de profesores, sus prácticas no se consideran deseables en esta $u$ otras instituciones.
\end{abstract}

Palabras clave: tutoría académica; gestión; profesor universitario; trayectorias; estudiante

\section{Outstanding advisors and their academic advising practices at a Mexican university}

\begin{abstract}
The present study focused on describing the academic advising practices of a group of professors with high scores on their advising performance as evaluated by their higher-education institution. Advising practices were assessed to determine whether they were good practices for standardization and dissemination. The narratives of 23 advisors and 16 students were recorded in eight focus groups by using a qualitative design. Transcripts were analyzed by using coding methods to determine advising views, forms of organization, communication styles, and the conditions in which advising interactions took place. The results showed that some advisor and student practices took place in times and spaces different from what their higher-education institution mandated in its regulation and management policy for advising practices. These practices posed professional and personal risks due to lack of institutional strategies and support. In conclusion, despite high commitment showed by advisors, their advising practices were not considered adequate for their and other higher-education institutions.
\end{abstract}

Keywords: academic advising; management; university professor; student trajectories 


\section{INTRODUCCIÓN}

Cuando se implementó la figura del tutor académico como un acompañante de las trayectorias escolares en los modelos flexibles, se depositaron aspiraciones no menores dentro de las que se contemplaron la disminución de la deserción y la reprobación, y el aumento de la eficiencia terminal; elementos asociados a calidad educativa. Un recorrido de cómo ha evolucionado la propuesta de las tutorías, las responsabilidades, funciones, y objetivos, muestra que estos han variado a través de los años y son diferentes dependiendo de la sociedad de la que se trate. Las concepciones varían porque se nutren de la interpretación institucional de documentos de políticas públicas que no son teóricos y que por tanto presentan los conceptos de una manera desarticulada. En México, por ejemplo, fue la Asociación Nacional de Universidades e Instituciones de Educación Superior (ANUIES) la que definió y delimitó el enfoque que se adoptaría. En la redacción de Rodríguez (2000) se expresaron una variedad de políticas nacionales e institucionales centradas en la consolidación de Cuerpos Académicos (grupos de investigadores asociados por líneas comunes de investigación) y el desarrollo integral de los estudiantes. En ese mismo documento se hizo énfasis en los programas de tutorías, en las tareas de vinculación de la universidad con el sector productivo y social, y en la transformación de las formas de gestión, planeación, y evaluación institucional. Todo ello se planteó con una visión al año 2020, por lo que es de esperar que pronto se proponga un nuevo horizonte de desarrollo para la educación superior. Por lo anterior, se hace necesario reflexionar sobre las transformaciones alcanzadas, en particular y para los fines de este documento, sobre las prácticas actuales de la tutoría académica en universidades mexicanas.

En el modelo de tutorías presentado por la ANUIES (2011) se incluyen estrategias de formación del tutor así como de evaluación de tutores y de los programas institucionales de tutorías. La gestión y evaluación de la práctica tutorial se guía con relación a las definiciones de tutoría que son consideradas por el caso en estudio. Por tanto, la presente investigación se interesa en conocer las características de la práctica tutorial de aquellos tutores con un alto puntaje en los instrumentos de evaluación y con amplio reconocimiento de los estudiantes, en coherencia con los discursos institucionales en sus dimensiones nacionales y de la propia institución. En este supuesto la hipótesis sería que estos tutores podrían estar desarrollando prácticas ejemplares, positivas y representativas que coadyuvan a los fines de la tutoría (apoyo al desarrollo integral, acompañamiento académico y contribución a la calidad de la educación). En este documento se presenta una primera aproximación al análisis de estas prácticas. Describir las acciones y razones de los tutores, permitirá saber si sus prácticas podrían dar lugar a una propuesta sobre buenas prácticas o prácticas deseables (Gordon, et al., 2007; Veselý, 2011) a través de las que se podrían sistematizar estrategias, estilos, herramientas y valores de los tutores con potencial de ser transferidos a otros contextos.

La investigación social en el ámbito educativo muestra un creciente interés en documentar buenas prácticas. Lograr lo anterior requiere fijar la mirada en condiciones y resultados de procesos institucionales y pedagógicos que alcanzan o superan sus objetivos planteados, obteniendo resultados favorables para los involucrados (Harrison, 2009) y valorados por la institución y sus actores, esto podría ofrecer pautas a seguir, tanto para los pares académicos como para las autoridades educativas. Los modelos destacados merecen ser observados dado que se sustentan en situaciones reales, brindan referentes empíricos; se convierten en un método para sistematizar, preservar y transmitir los aciertos a las nuevas generaciones (Guzmán, 2018; Veselý), y sientan bases para propiciar la tan buscada calidad en los procesos educativos. El vínculo que varias investigaciones han establecido entre la efectividad de los tutores y el éxito académico de los estudiantes (Barrón y Díaz, 2016; Holland, et al., 2020, Soria y Bultmann, 2014) es otro aliciente para saber qué elementos contribuyen al logro de tutorías efectivas. En esta investigación nos hemos propuesto documentar la experiencia de los profesores mejor evaluados sobre sus prácticas tutoriales en una universidad mexicana. Estos tutores evaluados por los estudiantes mediante instrumentos institucionales destacan por ser reconocidos por sus estudiantes en los indicadores ponderados por la institución. A partir de lo anterior nos interesa conocer las características de esta actividad y reconocer cuáles de estas son deseables de acuerdo a la literatura y cuáles son peculiares a la universidad de estudio.

Las reformas universitarias de los noventa sentaron las bases para instaurar la figura del tutor académico con un rol de acompañamiento continuo y cercano en los diversos ámbitos de la formación de los estudiantes (Bravo et al., 2019). La introducción de enfoques como el de la "formación integral", de "currículo flexible", de "la educación centrada en el estudiante", entre otros, afianzaron la necesidad de mover el foco de la formación puramente académica a otras áreas identificadas como cruciales en los proyectos de vida de estudiantes universitarios inmersos en dinámicas escolares con esta nueva propuesta (Venegas y Garaín, 2020). Así, se planteó que un académico, conocedor de los planes y programas de estudio, avezado en los planteamientos pedagógicos y curriculares de la universidad y los programas correspondientes, en espacios y procesos administrativos, en la estructura universitaria, en áreas clave para atender necesidades estudiantiles específicas, podría - paralelo al desempeño de sus funciones docentes-desempeñarse como esa figura orientadora en todos esos sentidos (He et al., 2020). Cabe resaltar que esta propuesta ensanchó el espectro 
de la formación universitaria (formación intelectual, humana, social y profesional) al mismo tiempo que propició la diversificación de las funciones de los académicos, quienes pasaron de, primordialmente hacer tareas docentes, a incursionar en la investigación, la administración universitaria y en la tutoría de los estudiantes (Ocampo et al., 2020).

En este escenario, las políticas de educación superior afianzaron la necesidad de consolidar la figura del tutor para un acompañamiento personal y para incidir positivamente en la retención y la eficiencia terminal (Artistimuño y Parodi, 2017; Holland, et al., 2020, Martínez y Elue, 2020). También se intentó compensar los posibles déficits formativos, contribuir a que los estudiantes hicieran frente a las adversidades que pudieran presentarse en su tránsito escolar, y guiar la estructuración de las rutas curriculares según el perfil específico deseado. Todos estos elementos consolidaron la figura del tutor y la acción tutorial como un servicio universitario adicional a la formación de profesionistas (Venegas y Garaín, 2020).

La figura de tutor académico surgió en universidades de Norteamérica, bajo condiciones y expectativas particulares, posteriormente fue adoptada en el resto del mundo bajo su propio contexto. Inicialmente, en las universidades del norte hubo personal específicamente contratado para desempeñar las tareas tutoriales cuya función era el acompañamiento académico durante la trayectoria formativa del estudiante (White y Schulenberg, 2012), esto era demandado de un modelo curricular flexible que resultaba confuso y desmotivante para los estudiantes, y a lo cual se le atribuyó los casos de abandono de los estudios (Harrison, 2009). En países de Latinoamérica el auge de la tutoría se encuentra en la generación de indicadores de calidad (Rodríguez, 2000) demandados por políticas y programas externos a las universidades que se apropiaron de los mismos objetivos de la tutoría de Norteamérica de los años 90 . Como sabemos, el foco de las tutorías estaba en la retención del estudiante para así evitar pérdidas financieras para las universidades. Expresado así, ambos universos, el del norte y de latinoamérica, han manejado los mismos elementos y rasgos neocorporativistas de organizaciones supranacionales como el Banco Mundial o la OCDE (Drake, 2011; White y Schulenberg, 2012).

En México el surgimiento de las tutorías y la modificación de la organización de las universidades y de las funciones del profesor fue en una parte importante una respuesta a las demandas administrativas, financieras y de evaluación de instancias como la ANUIES y el PROMEP (Programa para el Mejoramiento del Profesorado). Estas instancias reinterpretaron las políticas internacionales iniciando una agenda nacional en la que las actividades de tutorías formaban parte de los diversos programas de incentivos de educación superior para dirigir el desempeño de los académicos hacia la diversificación de la carga laboral (Ocampo et al., 2020); imprimiendo así, una dinámica peculiar en el ejercicio de las tutorías, con un sentido distinto a la universidad norteamericana. Aunque las actividades de diversificación de la carga se presentan con una envoltura discursiva de fomento a la calidad, en la práctica se hace evidente que el peso del incentivo abre espacio para otro tipo de lógicas que se expresan en intereses personales, como lo es mejores puntajes de evaluación y con ello una mejor remuneración (Baldwing y Marsha, 1985).

Este contexto de políticas e instituciones es importante para dar sentido a la literatura sobre tutorías que estudia las dinámicas tutoriales de las universidades anglosajonas, así como también, brinda un posicionamiento para abordar lo que sucede en Latinoamérica. Por tanto, este estudio contribuye al entendimiento de las tutorías de manera contextualizada para nuestra región.

\section{OTROS ANTECEDENTES}

Pese a que ya han transcurrido casi 30 años desde que las políticas universitarias han formalizado, ampliado, diversificado y sistematizado las tareas tutoriales, algunas investigaciones sobre los logros y resultados sugieren que no se han obtenido del todo los frutos esperados (Caldera et al., 2015). Autores como White y Schulenberg (2012) advierten que la forma en que se han impartido las tutorías ha soslayado su carácter académico y formativo circunscribiendo el quehacer tutorial a lo burocrático-administrativo. Otros acercamientos al tema exhiben que, en su mayoría, las tutorías se llevan a cabo como un requisito laboral, con poco compromiso y planeación por parte de los involucrados, e incluso con desconocimiento sobre las áreas en las que se debe desempeñar el tutor. También hay estudios que subrayan logros y lo apremiante que se hace el rol tutorial en modelos educativos diseñados para contar con esta figura. Venegas y Garaín (2020) y Holland, et al., (2020) identifican varias dificultades resueltas por los estudiantes gracias a la intervención de un tutor; describen a las tutorías como una estrategia en favor de los estudiantes, como un servicio que la universidad les brinda de manera individualizada para enfrentar las vicisitudes de la carrera universitaria.

Volviendo a los orígenes y el desarrollo de las teorías, Harrison (2009) explica que lo que hoy identificamos como 'teoría sobre tutorías' tiene sus antecedentes en las teorías surgidas en los sesenta sobre el desarrollo y bienestar de los estudiantes universitarios. Esas teorías, principalmente de corriente psicológica, explica la 
autora, no fueron pensadas para tutores, sino para que directivos, profesores y administradores pudieran brindarles a los estudiantes mejores herramientas para la vida adulta y profesional. White y Schulenberg (2012) comparten esta visión explicando que el objetivo original de las tutorías era "facilitar el desarrollo psicosocial de los estudiantes" (p.13). En años más recientes, el acercamiento a las tutorías ha tomado otros matices orientados a definirlas, delimitar sus alcances, identificar las cualidades y características de un buen tutor, establecer cómo debe ser la relación tutor-tutorado, qué medios se usan, y cuál debe ser el soporte que la institución debe brindar para que se logren los objetivos (Drake, 2011; Harrison, 2009; He et al., 2020).

Bajo estas coordenadas, se han elaborado diversas propuestas de lo que se debe considerar en el análisis de las tutorías. Así, por ejemplo, autores como Harrison (2009) plantea que el análisis de las buenas prácticas debe primordialmente entender cómo es la relación tutor-tutorado. Ella propone un análisis que distinga las diferencias entre las funciones tutoriales, las características de una tutoría y las cualidades de los tutores. Por su parte, White y Schulenberg (2012) hacen hincapié en el aprendizaje que debe resultar de una buena tutoría. Según ellos, mirar a las tutorías como un puro "seguimiento administrativo de los requisitos del grado" (p.13), mengua la relevancia que pueden tener las tutorías. Básicamente, postulan que una buena tutoría propicia que los estudiantes comprendan el significado de su curriculum universitario, que puedan sintetizar su experiencia de aprendizaje de manera global, que se gradúen entendiendo por qué eligieron una ruta curricular determinada. Pero, además, subrayan White y Schulenberg (2012) "la tutoría debe ayudar a los estudiantes a ver más allá de sus metas ocupacionales inmediatas hacia el mundo exterior a sus trabajos (...) Los estudiantes deben estar preparados para ocupar su lugar como participantes activos en una sociedad democrática en lugar de ser consumidores pasivos de bienes y servicios cívicos".

Por su parte, autores como He et al. (2020) proponen una tipología de tutorías que considera cinco enfoques: el basado en la información, el de intervención, el holístico, el de resultados de aprendizaje de los estudiantes, el de fortalecimiento y desarrollo de capitales. Ellos explican que no se trata de enfoques excluyentes, sino que pueden complementarse entre sí; reconocen que las instituciones, y a su vez los tutores suelen darle mayor auge a dos o tres de éstos. Así, el enfoque basado en la información es de naturaleza prescriptiva, propiciando la transmisión de datos para que el estudiante entienda y pueda transitar mejor por la institución y sus procesos. En el enfoque basado en la intervención el tutor asume un rol intrusivo, proactivo, de injerencia en situaciones críticas para aminorar los efectos en las trayectorias y el desempeño estudiantil. En el enfoque holístico el tutor apoya los diferentes aspectos que la universidad se ha propuesto desarrollar como parte de la educación integral. El enfoque de los resultados de aprendizaje busca fortalecer los aspectos pedagógicos y académicos de la experiencia escolar. Finalmente, el enfoque de fortalecimiento y desarrollo de capitales procura que los estudiantes incrementen sus recursos y estrategias para su bienestar completo. De igual forma, estos mismos autores puntualizan que, así como hay enfoques variados de las tutorías, quienes desempeñan las tareas tutoriales entran al campo con diferentes capitales profesionales que inciden en su desempeño. Ellos identifican tres tipos de capitales profesionales: el humano, el social y el de decisión. Abogan por un soporte institucional que dote a los tutores con estos capitales (He et al., 2020).

Aparte de las propuestas encausadas en entender qué, cómo y qué tipo de tutorías hay, autores como Amador y Amador (2014) aportan elementos sobre los medios que se pueden utilizar para llevarlas a cabo. Ellos explican que el acercamiento de los estudiantes a sus tutores puede ser uno de los mayores retos para las instituciones. Así, plantean una propuesta que considera el uso de las redes sociales como instrumento para facilitar la comunicación, hacer el acercamiento fácilmente accesible, barato, eficiente, continuo; desformalizar los espacios de acercamiento y por tanto facilitar el acercamiento. Amador y Amador (2014) identifican que factores como la edad, el sexo, la cultura, y el tiempo afectan el acercamiento de los estudiantes con sus tutores; de tal suerte que usar métodos convenientes para los estudiantes, aunque no institucionalizados, puede disminuir el reto del acercamiento tutor-tutorado. No obstante, como explicamos en los apartados de análisis y conclusiones, hay aspectos que se deben cuidar en la gestión de la comunicación y el desarrollo de la confianza para no vulnerar la privacidad de las partes involucradas.

Puntualizando sobre características que son valoradas de la acción tutorial, los mismos autores que revisan antecedentes, enfoques, tipologías y herramientas, brindan directrices al respecto. Por ejemplo, Harrison (2009) identifica que el conocimiento que posee el tutor sobre la institución, los cursos, programas, procesos, oficinas, fue la característica más valorada por los participantes de su estudio. A los estudiantes les interesa que sus tutores "sepan", pero también que sean organizados y que revisen sus expedientes antes de verlos. De ahí sobresalen características como cuidar, en sus palabras "fomentar y nutrir a los estudiantes", esto "incluye, pero no se limita a ser alguien que ayuda, que tiene ideas y recursos; para quien los estudiantes son una prioridad y los tutores puede ser una buena influencia" (p. 363). Según ella, también hay cualidades morales o virtudes como "la integridad, veracidad, honestidad, confianza... el cuidado". Otro tipo de características bien valoradas incluye la accesibilidad, la capacidad de comunicación, la disponibilidad y la buena organización, que sean amigables, alguien con quien es fácil hablar, abiertos, comprensivos, que mantengan contacto cercano, "que contesten correos electrónicos rápido, que tengan tiempo libre y que estén 
disponibles a la conveniencia de los estudiantes". White y Schulenberg (2012) coinciden en que el conocimiento de los tutores es clave en su desempeño, pero su preocupación principal está en las funciones de los tutores subrayando que éstos deben llevar a los estudiantes al entendimiento de las diversas rutas curriculares que pueden tomar y de las razones para elegir una u otra.

\section{METODOLOGÍA}

En este apartado se exponen datos contextuales sobre la universidad en la que se llevó a cabo la investigación, sobre cómo administra ésta su programa de tutorías y sobre el tipo de estudio que realizamos para contestar las preguntas de investigación planteadas.

\section{La universidad de estudio y su sistema de tutorías}

Esta investigación se llevó a cabo en la Universidad Veracruzana (UV), ubicada en la región sur-sureste de México. Es una institución pública con cinco campus distribuidos a lo largo del Estado. Ofrece 186 programas de licenciatura a una matrícula de 62,115 estudiantes, con una planta académica de 6,235 profesores, de los cuales $57.15 \%$ son de tiempo completo. Sus actividades se desarrollan a través de las funciones sustantivas de docencia, investigación y extensión de los servicios científicos, profesionales, artísticos y culturales.

En 1999 la UV instauró un modelo educativo que actualmente está centrado en el estudiante, se apoya en el enfoque por competencias y el diseño de planes de estudios flexibles, en el que la tutoría es una estrategia de apoyo y acompañamiento durante la trayectoria académica de los estudiantes. La universidad plantea que a través de los tutores se apoye a los estudiantes en la solución de problemas de tipo académico y burocráticoadministrativo, promoción de su autonomía y orientación de su trayectoria. Las acciones de tutoría se organizan mediante el Sistema Institucional de Tutorías (SIT) integrado por el coordinador, los profesores tutores de dos modalidades: tutoría académica y de enseñanza tutorial, los estudiantes que apoyan las actividades tutoriales denominados monitores, y los estudiantes tutorados. El sistema, a nivel institucional, es coordinado por la Dirección General de Desarrollo Académico e Innovación Educativa (DGDAIE) a través del Departamento de Apoyo a la Formación Integral del Estudiante. En cada entidad académica se tiene un coordinador del SIT responsable de la organización y seguimiento de las actividades tutoriales.

Como parte de los objetivos de educación integral, se desarrollan dos tipos de tutoría: la Enseñanza Tutorial (ET) y la Tutoría Académica (TA). Los requisitos, atribuciones y obligaciones de los tutores se especifican en el reglamento del sistema tutorial. La ET se realiza a través de Programas de Apoyo a la Formación Integral (PAFI); su objetivo es apoyar a los estudiantes en el aprendizaje de contenidos curriculares o ampliar su formación disciplinaria o artística; también se orienta a desarrollar capacidades de investigación y de apreciación artística -éstas dos últimas opciones otorgan créditos a los estudiantes-, la ET puede ser sugerida y programada como resultado de las necesidades detectadas en la TA. La TA da seguimiento a la trayectoria escolar de los estudiantes durante su formación, pretende orientar al estudiante en la construcción de trayectoria en función de un perfil profesional, tomando en cuenta sus expectativas, capacidades e intereses. La TA es la que concentra mayor número de profesores y estudiantes, el reglamento estipula que cada estudiante debe contar con el acompañamiento de un tutor. Con base en los datos proporcionados por la Dirección General de Desarrollo Académico e Innovación Educativa, la TA se realiza por 3,547 tutores con una cobertura de $87 \%$ de la matrícula total del pregrado. El número promedio de estudiantes por tutor varía de acuerdo con el total de estudiantes por área académica de formación, en el área Técnica es de 16, Humanidades 14, Económico Administrativas 19, Ciencias de la Salud 16, Ciencias Biológicas y Agropecuarias 13 y en Artes 7.

De acuerdo con los documentos institucionales, la TA es llevada a cabo por el personal académico en funciones de docencia e investigación, quien realiza actividades académico-administrativas de seguimiento a la trayectoria de los estudiantes, el diseño de un plan de trabajo, la organización de reuniones informativas, de apoyo y orientación, la integración y actualización de expedientes individuales y la elaboración de reportes sobre la situación académica de los estudiantes bajo su tutela. Para el desarrollo de estas actividades, los tutores cuentan con el sistema de registro y seguimiento de la actividad tutorial, en este sistema se accede a la información académico-administrativa de cada estudiante (datos de identificación, avance crediticio, calificaciones, horario, situación escolar, información socioeconómica, resultados del examen de ingreso) necesaria para la planeación de la trayectoria académica y el seguimiento de la situación escolar. En cada periodo escolar, se realizan al menos tres sesiones presenciales obligatorias que permiten orientar a los estudiantes en tres procesos administrativos: Planeación de las materias a cursar en el siguiente periodo escolar (PLANEA), Proceso de Pre-Inscripción en línea (PreIL) y Proceso de Inscripción en línea (PIL). Cada tutor registra en este sistema el plan de trabajo de las sesiones con base en el porcentaje de créditos aprobados por los estudiantes: $0 \%$ a $40 \%, 41 \%$ a $70 \%$ y $71 \%$ a $100 \%$, así como los reportes de cada sesión, 
en los que se mencionan los aspectos académicos, profesionales y personales que tuvieron un impacto en el desempeño académico del estudiante, así como, los acuerdos establecidos en las sesiones de tutoría.

La TA es evaluada semestralmente; los resultados sirven para ponderar las participaciones de los académicos en programas de estímulos, como méritos para quien desean mejorar su tipo de contratación o para quien participa en los programas de incentivos, e idealmente, como directrices para mejorar el servicio tutorial. Para la evaluación se utiliza un instrumento que se basa en el reglamento de tutorías y se aplica al estudiante cada final del semestre. Las dimensiones son: A) Apoyo académico, B) Orientación profesional, C) Desarrollo personal, D) Integración y permanencia, E) Inclusión de temas y actividades de interés o atención a necesidades e historial académico, F) Resolución de dudas o canalización a instancias de apoyo, G) Disponibilidad de tiempo por parte del tutor. El instrumento distingue un proceso diferenciado de atención según el tiempo de permanencia del estudiante: inicial, intermedio y avanzado. Cabe destacar que en este proceso de evaluación las variables $A, B, E, F, y G$ responden al cumplimiento de las obligaciones de los tutores que se establecen en el marco normativo del SIT. No obstante, las variables $C$ y D no se identifican dentro de las funciones normadas en el reglamento de tutorías.

Para coadyuvar en las tareas que los dos tipos de tutoría conllevan, y apoyados en las directrices de la ANUIES (2000) la UV ha diseñado cuatro cursos para brindar y fortalecer los conocimientos y competencias necesarios en el trabajo tutorial. Los cursos se ofrecen de acuerdo a la demanda de los interesados y van dirigidos tanto a académicos, como a estudiantes que cubren el perfil para participar como monitores. Se trata de cursos en constante revisión y actualización debido a las continuas adaptaciones y al desarrollo de herramientas o plataformas digitales que la UV implementa como apoyo a la construcción y seguimiento de las trayectorias estudiantiles.

\section{Tipo de estudio y herramientas metodológicas}

La presente investigación se apoya en herramientas analíticas y metodológicas de corte cualitativo. Esta lente de observación nos permite acercarnos al conocimiento de los procesos, las estrategias, las dinámicas (Berg, 2001) del trabajo de los tutores con mejores resultados en las evaluaciones institucionales. Se utilizó la estrategia del grupo focal (GF) por su idoneidad para facilitar el intercambio de ideas y porque permite observar posicionamientos individuales, acuerdos y desacuerdos entre los participantes. Adicionalmente, el marco de la reflexión colectiva ofrece un potencial pedagógico y reflexivo que parte de las dinámicas de la interacción grupal (Kamberelis y Dimitriadis, 2011).

En el GF de tutores trabajamos con las siguientes temáticas: 1) estrategias para conducir las tutorías individuales; 2) El rol que juegan los tutorados en la dinámica de tutorías; y, 3) Las condiciones de la institución para dar soporte a la actividad tutoral. En el GF de estudiantes tutorados abrimos la discusión en torno a cinco temas: 1) la relevancia de las tutorías en sus trayectorias formativas; 2) Su opinión sobre la gestión de las tutorías; 3) El deber ser de las tutorías; 4) Opiniones sobre la práctica de evaluación y el instrumento de evaluación de la tutorial, y; 5) La relación entre tutor-tutorado. Durante el desarrollo de los GF se mantuvo apertura y flexibilidad para explorar temáticas que los participantes abordaron, los conductores del GF dieron atención y continuidad a nuevos temas, así como reorientaron la discusión cuando fue necesario. La selección de participantes del GF de profesores utilizó los resultados del instrumento de evaluación para seleccionar a los tutores con mayor puntaje en dos periodos escolares: agosto 2017 a enero 2018 y febrero-julio 2018 por cada una de las cinco regiones donde la UV ofrece programas: sur, montaña, centro, puerto y norte. Cada grupo se conformó por los siete participantes que aparecieron con el puntaje más alto en el instrumento de evaluación institucional en los semestres agosto 2018 a enero 2019 y febrero-julio 2019. Seleccionamos a los siete mejores por región sin establecer un rango específico de puntaje alcanzado.

Los GF con estudiantes tuvieron el propósito de ofrecer una visión para complementar la de los tutores y como un elemento para enriquecer los datos desde la mirada del receptor de la tarea tutorial. Se consideró también que documentar la experiencia del estudiante permitiría de alguna forma validar los relatos de los profesores. La emergencia sanitaria provocada por el COVID-19 interrumpió el trabajo con dos de los GF en las sedes. Una vez que se redujeron las incertidumbres institucionales sobre las nuevas reglas de trabajo y habiendo ganado un poco de estabilidad en las inéditas circunstancias en las que nos encontrábamos, pudimos recuperar (de manera virtual) el trabajo con los GF de tutores. No tuvimos el mismo éxito para convocar a los estudiantes de esas sedes debido, entre otras muchas razones, a la falta de tecnología o de conectividad, o en otros casos, hubo distintas circunstancias de los estudiantes que les impidieron participar en los GF. Esto representó una limitante en el número de voces de los participantes. Continuamos con el estudio porque consideramos que la muestra ofrece suficiente variedad para ver a través de estudiantes que participaron los rasgos de las prácticas tutoriales y sus opiniones al respecto. Un elemento de interés que pueden ofrecer estos testimonios fue el momento en que fueron obtenidos (marzo 2020) donde se pudieron recuperar algunas menciones acerca de la crisis sanitaria. 
Participaron un total de 23 tutores y 16 tutorados, cuyas características fueron heterogéneas en términos de su programa de adscripción, tipo de contratación, años de experiencia y número de tutorados (para el caso de los tutores); y avance crediticio, programa y facultad a la que pertenecen (para el caso de los tutorados). Con esta riqueza representativa, se integraron cinco GF de tutores y tres de tutorados. Cada GF tuvo una duración de entre dos a tres horas, las participaciones fueron grabadas en audio, posteriormente transcritas y preparadas para ser analizadas mediante métodos de codificación y categorización (Berg, 2001). La identidad de los participantes es resguardada, por lo que todos los nombres que aparecen en este artículo son pseudónimos.

\section{Análisis de datos}

La codificación de los textos originados en la transcripción de los GF se hizo mediante el software de análisis cualitativo Atlas. Ti versión 9. El sistema de códigos se construyó como resultado del análisis de artículos y de los documentos instituciones en los que se describen las funciones de la tutoría y las responsabilidades del tutor.

El sistema de códigos consideró las siguientes dimensiones: definiciones institucionales, definiciones subjetivas sobre la tutoría y la función del tutor y descripciones del trabajo de tutoría. Ésta última incluye: los aprendizajes o desarrollos que se propone la acción tutorial, las acciones del tutor, las acciones del tutorado. Otros códigos identificaron estrategias de comunicación, procesos institucionales, espacios y otros recursos del tutor, del estudiante y de la institución para organizar, gestionar, facilitar o inhibir acciones relacionadas a la tutoría. En su conjunto los códigos pretendieron identificar las acciones, estrategias y herramientas que son movilizadas en el trabajo del tutor en la universidad. Los códigos también permitieron recuperar, relacionar y contextualizar el lenguaje y autodefiniciones que forman parte de la subjetividad de los tutores y estudiantes. Este sistema de códigos siguió en parte el análisis de Smith y Allen (2014) pues ofrece elementos descriptivos ya que se centra en las dimensiones del trabajo de los tutores.

Durante el análisis emergieron otros códigos necesarios para identificar particularidades del caso de estudio. Por ejemplo, la mención a eventos específicos como toma de materias, preinscripción, y otras referencias a instancias y herramientas de la institución. En algunos casos se desarrollaron códigos para identificar la variedad de objetos o acciones; por ejemplo, el código de tópicos de tutoría dio origen a un grupo de subcódigos para identificar la variedad de tópicos y la frecuencia de éstos según lo reportan estudiantes y tutores. Los códigos evolucionaron, se fusionaron y relacionaron según se avanzaba en la comprensión de las relaciones. Se desarrollaron notas analíticas a partir de estas relaciones con lo cual se elaboró un reporte de resultados.

\section{RESULTADOS}

Para responder a las preguntas planteadas en este estudio sobre las dinámicas del trabajo tutorial presentamos seis dimensiones que ayudan a describir y relacionar las miradas de profesores y estudiantes en el contexto institucional.

\section{Funciones y responsabilidades de los tutores}

Las definiciones institucionales se recuperan en el uso de un lenguaje mediante el cual el tutor y tutorado describen sus actividades. La normatividad institucional establece atribuciones y obligaciones. Las primeras son más de orden académico: el tutor ayuda a la elección de asignaturas, da seguimiento del desempeño del estudiante, brinda apoyo en el aprendizaje, orientando sus acciones a la conformación de un perfil profesional, realiza el diagnóstico de necesidades académica del estudiante y les da atención. Las obligaciones se establecen en un terreno administrativo, incluye trabajo de documentación de la acción tutorial mediante reportes, gestión de tiempo y espacio para la planeación y programación de actividades (Universidad Veracruzana, 2009). En la evaluación institucional de las tutorías se ponderan actividades de apoyo académico, curricular, pedagógico y profesional, pero también actividades de apoyo al desarrollo personal mediante orientación en la integración y la permanencia y el abordaje de temas de interés en las sesiones de tutorías.

En la lógica de atribuciones y obligaciones, tutores y tutorados dan nombre a sus acciones y les dan sentido dentro del marco institucional. Sin embargo, como se verá en la exposición siguiente, la alineación de los propósitos institucionales no se corresponde tan directamente con las condiciones para la actuación de los sujetos, ni tampoco esta actuación tiene el alcance que pueden suponer participantes e institución.

En el análisis de datos empíricos sobresale que el desempeño tutorial está fuertemente mediado por la forma en la que tutores y estudiantes conciben el rol del tutor. Se observó que en su discurso el tutor recupera cuatro dimensiones: (1) la personal, que incluye una visión de las tutorías y del trabajo en la institución y sobre el 
estudiante; (2) el conocimiento de la institución y su experiencia en ella, que le permiten organizar y llevar a cabo estrategias de intervención y gestión; (3) el conocimiento de teorías psicopedagógicas y normativas que dan un lenguaje para nombrar y reflexionar sobre la acción tutorial; y (4) el contexto y soporte institucional que introduce elementos básicos que limitan y potencian acciones de gestión y comunicación entre los participantes.

Los testimonios compartidos son representativos del discurso del tutor, combinan posturas personales, interpretaciones de la función de la tutoría, justifican estrategias para el desarrollo de la relación tutorial. El discurso del tutor mezcla constantemente, en su opiniones, reflexiones y justificaciones, elementos personales o marcos normativos y/o de ética académica, "...de una E.E [asignatura] del área básica y donde tenemos un índice alto de reprobación, entonces lo que hacemos es decirle que llegue a tiempo, que no falte, también no se debe de atacar al docente porque es nuestro compañero, sino darle estrategias para que ellos salgan adelante en esa E.E, que ellos se sientan que yo me intereso en sus problemas y puedan contarme y que de una u otra manera yo los puedo apoyar. En muchas ocasiones me ha pasado que se me acercan que les ha pasado algo y ya les digo que no se preocupen y vamos con el maestro y ya hablo con él y el joven, normalmente -es la regañiza como siempre lo imaginamos- en ningún momento lo evidencio y quedamos de acuerdo de que debe de hacer su parte como debe de ser y el muchacho responde (Raquel, tutora, Región Norte).

Las prácticas observadas orientan frecuentemente las tutorías a funciones informativas y para solucionar problemas relacionados a la toma de materias. Las acciones de dar y solicitar información son una parte importante de cómo profesores y estudiantes conceptualizan la función del tutor. Un estudiante argumenta sobre la importancia del tutor, "Sí es importante, pero ¿por qué? Bueno, para empezar, como dice su nombre, es el tutor. El tutor por sus conocimientos, bueno no solo por sus conocimientos, por estar en el ambiente universitario sabe de la administración, docentes, preinscripción, de vinculación y todo ello. Pues todo es una herramienta muy importante para nosotros porque nosotros no llegamos conociendo el ambiente de la universidad. Necesitamos de alguien. Es una herramienta muy importante porque nos ayuda en situaciones, prácticas como lo decía mi compañero, al realizar cierto trámite. Por ejemplo, que quiera cambiar de facultad, ir con el tutor "oiga ¿cómo está?, ¿cómo es el papeleo? ¿qué hago?” y cuestiones de esas de monitorear nuestra trayectoria académica” (Gabriel, estudiante, Región Sur)

Esta función informativa es también consolidada en las definiciones institucionales para la organización de las actividades, propone que la atención ocurra en sus tres momentos durante el semestre, el llenado de los informes y tareas informativas a los estudiantes sobre los programas y las actividades académicas y algunos elementos de la normativa del Sistema Institucional de Tutorías, como se verá más adelante, el inicio de las tutorías, consiste justamente en ofrecer información, estableciéndose así una de las funciones principales.

A pesar de que la institución establece un marco de espacio y tiempo para las tutorías, los testimonios de profesores y estudiantes ofrecen evidencia para reconocer que la práctica de atención tutorial se desarrolla en tiempos y espacios no considerados en los supuestos de la institución. Por ejemplo, para cumplir su tarea, los tutores realizan mayor número de sesiones de tutoría, lo que implica un mayor tiempo de atención, además de acordar espacios y medios de comunicación y horarios no considerados en la normatividad institucional (Silvia, tutora, Región Montaña; Brenda, tutora, Región Sur). En algunos casos las interacciones se originan como parte de la dinámica de acompañamiento, cuando el tutorado desea consultar al tutor para tomar decisiones, o para conocer la opinión del tutor sobre otras actividades académicas como la movilidad o trámites de becas y estancias. En estos casos, y de acuerdo con Alonso et al. (2018), la tutoría no es una función complementaria de la docencia, sino una acción integral. Esta cita ilustra algunas de las demandas del quehacer tutorial, "Cuando ves un mensaje dices ¿y ahora qué se le atoró a fulanito? y piensas que eso te va a llevar tiempo, te va a quitar un poco de tiempo que tú ya tienes previsto para otras cosas. Pues las dejas, les das ese tiempo y tratas de resolver, eso es compromiso." (Irais, tutora, Región Puerto)

En otros casos, la necesidad de los estudiantes y el compromiso del tutor para dar respuesta a demandas que se originan en situaciones de emergencia o potencialmente problemáticas, obliga a implementar otras formas de comunicación y atención como se relata en esta cita, "tres sesiones no son suficientes, hay que estar todo el semestre y hay que estar 24-7; yo coincido con mis compañeros, creo que si los estudiantes se atreven a hablar a deshoras es porque necesitan algo y porque no tienen otro apoyo, entonces el tiempo no es suficiente" (Maximiliano, tutor, Región Centro)

En los grupos focales se planteó la pregunta a los estudiantes sobre cuál había sido el proceso más difícil en la universidad, varios de ellos reconocieron los procesos de inscripción y toma de materias, "yo siento que a la hora de elegir las experiencias [asignaturas] con base al plan de estudios. Pero si repruebas alguna materia o cosas así, pues eso se va alterando y luego tú quieres meter materias, pero no te deja el sistema. Entonces el tutor te va diciendo 'no, pues tienes que hacer esto'. En ese aspecto de que uno quiere llevar materias, 
pero luego se complica. El tutor es el que me ha orientado 'mete estas materias para que no te vayas atrasando'. Sí me ha ayudado" (Sebastián, estudiante, Región Sur). Como puede observarse, la tutoría, conceptualizada por la institución, supone tiempos, espacios y tópicos que no describen del todo las acciones y necesidades de los sujetos; al mismo tiempo que las estrategias de los sujetos recuperan algunos de los recursos de la institución para la solución de problemas que al no ser suficientes incorporan elementos ajenos al discurso institucional.

\section{Las estrategias de comunicación en la atención tutorial}

La comunicación del tutor con el estudiante es una dimensión importante porque se relaciona con las funciones que atribuyen estudiantes y tutores a la tutoría, y también implica formas de comunicación como parte del desarrollo de una relación de confianza. Se distinguen tres formas en las que se lleva a cabo la interacción comunicativa entre el tutor y el tutorado: (1) la comunicación apegada a los calendarios institucionales, (2) la comunicación urgente, (3) la comunicación de seguimiento.

La comunicación como respuesta urgente, se presenta en dos tipos de situaciones. En la toma de materias, frecuentemente referida por estudiantes y tutores como una situación problemática dado que la oferta de las materias no cubre las expectativas o necesidades consideradas durante el proceso de planeación de la trayectoria. Algunos profesores prevén varios escenarios, pero en la mayoría de los casos esto no es suficiente para orientar todas las tomas de decisión del estudiante, "Sí, fíjense que en el caso de los chicos de la facultad lo que hacemos es irnos a los horarios de semestres anteriores, y más o menos ellos buscan, arman el horario de acuerdo con ese horario anterior, pensando en que es muy probable que sean el mismo horario... Ahora el grave problema... es la inscripción en línea como decía la maestra Norma, que ya ahí los chicos me hablan por teléfono o en WhatsApp 'oiga estoy aquí inscribiéndome y no me aparece la materia tal, que esto, que lo otro'. Entonces eso, la primera vez fue terrible, fue una pesadilla, porque colgaba con uno y el otro y así, el sistema en general de la UV tiende a tener esos problemas cada semestre." (Esmeralda, tutora, Región Puerto).

Para comprender la urgencia y trascendencia de la toma de materias ha de considerarse que, en muchos casos, el estudiante debe cumplir con una carga de créditos, aún y cuando implique inscribirse a materias no consideradas en el primer plan de su trayectoria. Segundo, en algunos casos la reprobación de una materia puede ser causal de baja, por lo que es importante evitarla o considerarla en otro momento del trayecto. Y, tercero, la toma de materias debe completarse en un marco de tiempo limitado, que, como explica el trabajo de Ocampo-Gómez (2021), causa ansiedad y frustración en los estudiantes. En ese contexto, la comunicación y consulta del estudiante debe recibir respuesta inmediata por parte del tutor. La solución de profesores y estudiantes ha sido utilizar aplicaciones como Whats App, y Facebook y llamadas telefónicas y el mensaje de texto. El uso del correo electrónico es limitado, así como la plataforma de seguimiento de tutorías que además no ofrecen este elemento sincrónico y de respuesta inmediata. Sobre este tema encontramos el siguiente relato, "yo lo que hago en los días de inscripción en línea, junto con la inscripción en ventanilla, es estar extremadamente al pendiente, para alcanzar los lugares. Entonces ahí si es como dedicación de esos de Twenty-four-seven. Así estar súper al pendiente para que ellos no pierdan los lugares, porque nosotros estamos aquí en esta facultad de ingeniería mecánica y ciencias navales, ya tiene tiempo que implementamos un sistema adicional al PLANEA [sistema de ayuda a la planificación de trayectoria]. Es un sistema externo y en donde permite ver cuántos lugares se tiene disponible y cómo van dejando lugares, van abriéndose lugares, de tal manera que nos permita ver esa fluctuación y aprovechar... de inmediato sabemos cuándo ya hay lugares" (Luz, tutora, Región Puerto).

En una perspectiva práctica Amador y Amador (2014) explican la conveniencia de este tipo de medios, lo que no exploran en su análisis es cómo tutores y tutorados se ven expuestos al revelar información personal y al mismo tiempo abrir canales de comunicación no regulados institucionalmente. Aquí otra perspectiva de las plataformas institucionales, "porque sencillamente no se actualiza el sistema, entonces yo llevo -la retículabien controlada, individual, de qué experiencias educativas están cursando [los estudiantes en tutoría] y si la están llevando en primera o en segunda. También ahí mismo tengo el control de los créditos acumulados y de los que lograron pasar. Entonces cada vez que ellos tienen alguna duda, por ejemplo, en la preinscripción en línea o la inscripción y quieren por ejemplo llevar otra materia que no habíamos seleccionado en la planeación yo siempre recurro a ese archivo y ahí puedo sugerir cuáles otras materias pueden pedir. Todo eso ya lo hacemos en línea, ya sea por el WhatsApp o ya sea que me hablen por teléfono directamente al momento de hacer la inscripción de tal manera que el apoyo siempre lo van a tener, es muy raro a menos que yo no haya podido contestar el teléfono, pero en el primer momento que yo pueda yo enseguida me comunico con ellos. Ellos saben que en cualquier momento pueden contactarme, que tarde que temprano, lo más pronto posible, van a tener una asesoría o una ayuda externa” (Mónica, tutora, Región Puerto, 63). 
La toma de materias, por las restricciones de oferta y los procedimientos administrativos existentes son un permanente reto que suele exigir la reconstrucción inmediata de la trayectoria formativa. Esta acción de acompañar al estudiante en la construcción de la trayectoria es reconocida por tutores, estudiantes y planes institucionales, pero es también una función ampliamente reconocida en la investigación (Alonso et al., 2018). En el caso estudiado, los tutores y estudiantes deben ajustar su planificación a una oferta de cursos imposible de predecir. Esta práctica es contraria a la pretensión de un proceso de reflexión sobre la trayectoria acompañada del desarrollo de una perspectiva profesional. Las condiciones de la inscripción imponen una lógica distinta emergente, al mismo tiempo que el currículum contiene reglas de acreditación que en ocasiones hacen que la selección de una materia sea un riesgo para el estudiante, pues su reprobación podría implicar la baja del programa o desencadenar otros problemas que podrían implicar varios semestres antes de solucionarse. Ocampo (2021) hace un análisis que profundiza sobre los retos que enfrentan los estudiantes en la conformación de su carga académica al inicio de cada semestre. El testimonio que sigue añade información al respecto "el PLANEA es un rudimento que sirve administrativamente, el niño ahí genera sus sueños, y dice yo quiero todas estas materias y cuando llega -porque en teoría sirve para la oferta académicala oferta académica- pues no, doscientos estudiantes solicitaron una experiencia educativa y pues en tu banco de horas solo la vas a poder ofertar para cien, entonces el estudiante "pero maestra es que yo lo pedí, pero es que yo si entre a PLANEA'y demás." (Mariela, tutora, Región Centro.).

El evento de la toma de materias marca fuertemente, en la práctica, las funciones del tutor y las expectativas del estudiante, así como las formas de atención y las herramientas de comunicación requeridas. Estas actividades de adecuación de la trayectoria académica a las circunstancias de la oferta, va construyendo en los tutores y estudiantes una representación de la atención a la trayectoria que ha perdido su sentido académico, para ser una estrategia de sobrellevar los procesos administrativos del currículum. Este es el comentario de un estudiante que refleja el concepto 'apoyo' en la trayectoria en función de sortear las dificultades en la toma de materias: "ella [la tutora] me ha ayudado a llevar mis materias en tiempo y forma, para no atrasarme en ninguna forma, me ha ayudado a ver las materias que debo de ir llevando conforme voy avanzando, cuáles puedo adelantar, cuáles no, y en qué momento debo de tomarlas." (Javier, estudiante, Región Norte).

Ya establecida una comunicación mediante plataformas síncronas, otras formas de interacción siguen utilizando estos canales. Por ejemplo, solicitar y enviar información entre estudiantes y tutores, reforzando el uso de estos canales, la conveniencia demostrada y el hecho de que, de acuerdo a algunos profesores, los medios de información institucional pueden contener información desactualizada, "un grupo en WhatsApp, yo siempre he sido también como medio enemiga de los grupos. Solamente grupos ahora que estamos con esto de la contingencia [en referencia a la emergencia sanitaria] y con mi grupo de tutorados siempre, desde que iniciamos tenemos un grupo. Ahí los tengo a todos, no están separados por generaciones, están todos juntos, justo porque a veces la duda de un chico de primer semestre la resuelve un chico de cuarto o de sexto semestre ¿no? Entonces también, yo a veces estoy ocupada en clases. Entonces ha habido ocasiones en que veo el mensaje de que había una pregunta y ya alguien le respondió... También tenemos un grupo en face [en referencia a FaceBook], y ahí les voy pasando información y actividades" (Ximena, tutora, Región Centro).

Los estudiantes pueden buscar directamente al profesor cuando éstos tienen cubículo o casualmente en encuentros en pasillos. No se cuenta con información específica sobre la incidencia de las sesiones individuales. En algunos casos, por los relatos de los estudiantes y tutores es posible que éstas puedan ocurrir más de dos veces adicionales a las ya programadas, como se menciona en estos relatos: "Atender de manera puntual alguna duda o inquietud de los chicos, no importa si no hay sesión o si hay sesión. siempre trato, si recurren a mí, atenderlos (Mónica, Región Sur). "A parte de las tutorías que nos piden, que son tres, también les propongo citas extraordinarias por un tema o alguna situación que él requiera, algo particular" (José Antonio, tutor, Región Sur)

\section{Los tópicos de la tutoría según profesores y estudiantes}

Los tópicos de las tutorías representan los temas y problemas que los tutores y estudiantes abordan durante sus sesiones, en ese sentido, son el contenido y propósito de la sesión tutorial. Los tópicos también permiten visualizar las funciones que la tutoría cumple y ampliar las definiciones institucionales. Se realizó un inventario de los tópicos según se muestra en la Figura 1, puede observarse dos tópicos que son los más frecuentes: la solicitud o entrega de información y discusión de la trayectoria. En el primer caso, la actividad informativa consiste en seleccionar, presentar -por parte del tutor-, o solicitar -por parte del estudiante- información sobre fechas, eventos, trámites y datos institucionales. En muchos de los casos se trata de información que podría ser entregada o consultada por otras vías. 
En el caso del tópico "trayectoria" los participantes pueden hacer referencias a aspectos curriculares, el cumplimiento de créditos, la toma de materias, información de trámites administrativos principalmente asociados a la inscripción; y aunque esto parecería confirmar que la función central de acompañamiento a la trayectoria se cumple en las prácticas tutoriales, no es clara la trascendencia de éstas cuando, como se ha comentado, el proceso de toma de materias introduce cambios emergentes poco relacionados a la reflexión y perspectivas profesionales que obliga a los actores a cambiar los planes.

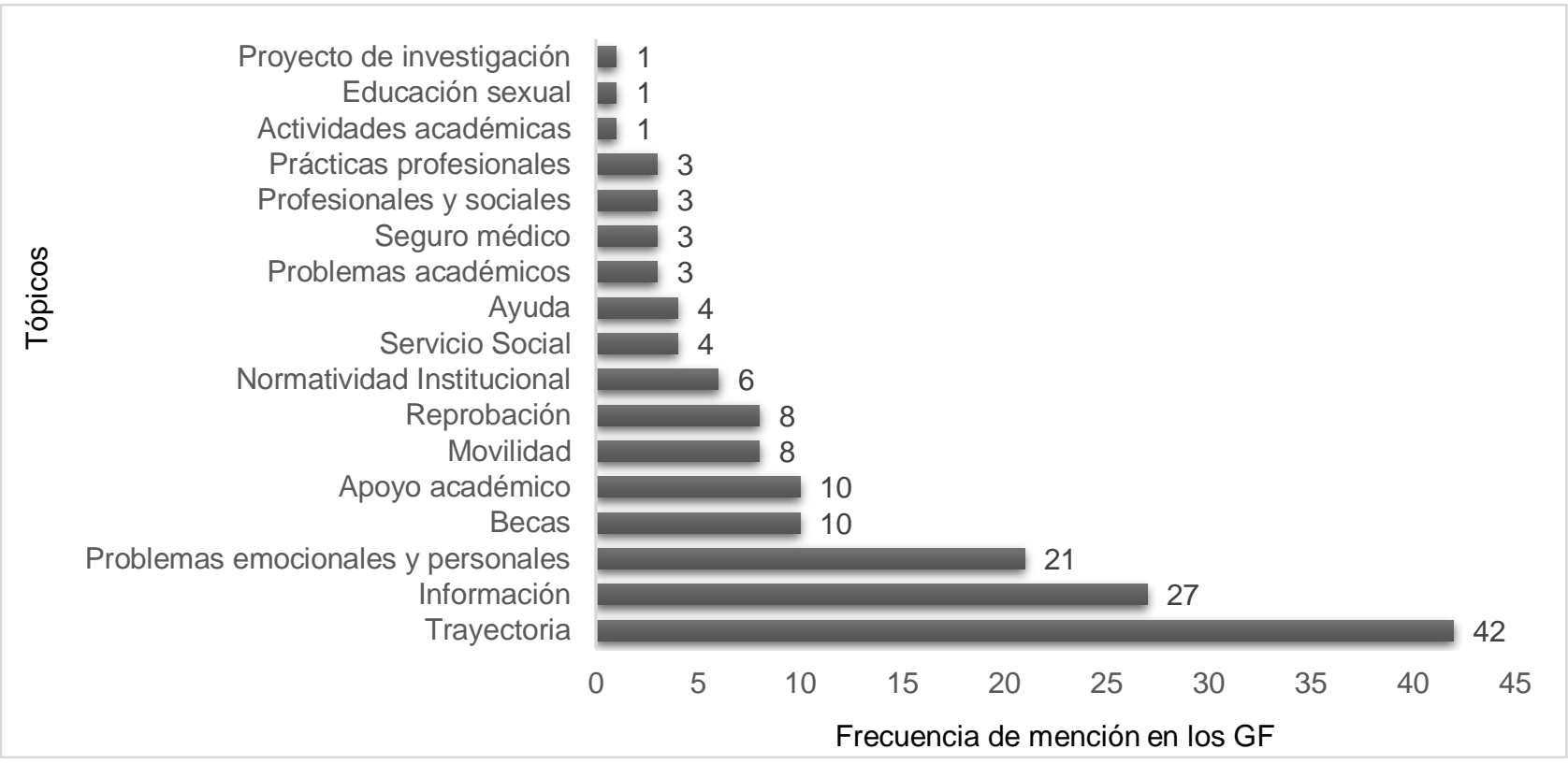

Fig. 1: Tópicos con mayor frecuencia de mención en los Grupos Focales de tutores y estudiantes

White y Schulenberg (2012) argumentan sobre la importancia de que las tutorías vayan más allá de un seguimiento administrativo de los requisitos de grado; tutorías que primordialmente reditúen en aprendizaje, en una visión global de lo que se logró y de lo que se desea hacer con la formación obtenida. Los resultados de nuestra investigación muestran que el eje académico y formativo se encuentra constantemente limitado en la solución a problemas de gestión institucional y a las carencias de soportes institucionales para fortalecer la mirada académica de la tutoría. El caso del tópico "trayectoria" es ilustrativo de este conflicto.

Retomando los modelos de tutorías planteados por He et al. (2020) se hace evidente que tampoco priva el enfoque holístico en la práctica tutorial. En los datos se encuentra un énfasis en las acciones informativas y de intervención directa en las cuales el tutor prescribe las soluciones y rutas que tomar e incluso interviene directamente para solucionar un problema administrativo. Lo anterior es ilustrado en esta reflexión, "primero les doy la información general que les tengo que dar, también en la coordinación siempre nos dicen, tal fecha es el día de tutoría y los temas obligatorios que tienen que darles son estos, esto y esto, por ejemplo, tienen que avisarles que ya mero va a ser la acreditación y que a algunos los van a llamar, nos dan alguna información que hay que darles (...) cuando me hacen preguntas, lo que les digo es, ¿sabes qué?, no lo sé, pero ya lo anoto, lo voy a investigar y en cuanto lo sepa te aviso, te mando un correo." (Fernando, tutor, Región Centro)

Por último, cabe detenerse a reflexionar sobre la frecuencia con la que aparecen tópicos sobre problemas emocionales y personales. Si bien la normatividad institucional recomienda que se canalice a otras instancias, y una parte de los profesores lo hace, sobresale la necesidad de un apoyo psicológico a los estudiantes. Una estrategia que los tutores han reportado para el desarrollo de confianza con el tutorado es dar lugar a conversaciones personales; sin embargo, en algunas ocasiones el tutor no parece advertir que supone un riesgo el no distinguir lo que es una conversación sobre gustos personales y cuando se introduce a temas emocionales y personales. La mayoría de los tutores no están capacitados para brindar este tipo de apoyo, sin embargo, la necesidad aparece de manera cotidiana en sus interacciones con los estudiantes. Esta necesidad del estudiante de un apoyo emocional no remite a los orígenes de las tutorías, donde se buscaba el bienestar de los estudiantes (Harrison, 2009) y la importancia de otro tipo de espacios para facilitar su desarrollo psicosocial (White y Schulenberg, 2012).

Sobre el tema anterior compartimos estas experiencias, “... y pues de ahí sus cuestiones personales y como algunos maestros lo han mencionado pues sí efectivamente a veces y nos metemos en temas personales no hay de otra. Porque a veces están a punto de perder todo por una cuestión personal, se ahogan en un vaso 
de agua o voy a decir algo muy grave. He encontrado casos de muchachos con enfermedades, incluso los canalizamos pues a atención médica, cuestiones psicológicas también y ya también pues cosas más graves e intentamos pues orientarlos. Ha habido muchachos con situaciones terroríficas y en ese momento estamos ahí, estamos para apoyarlos, porque actualmente hay temas de mucho terror, cuestiones delincuenciales $y$ eso entonces hay muchachos que han sufrido esas situaciones y ahí estamos, $y$ en ese momento los acompañamos." (Francisco, tutor, Región Puerto). "Mi sorpresa fue que identifiqué muchísimos problemas que no sabía [explica situaciones de violencia, de salud, e incluso de crimen]...mis tutorados han visto ese apoyo hasta donde compete a mi persona sin meterme en más situaciones porque también tenemos a veces tutorados que pues que no son muy buenas personas porque andan en otras situaciones pues también tratar de guardar y vigilarlos el interior de la facultad, pues que no tengan esos comportamientos." (Ramón, tutor, Región Montañas)

\section{La gestión de las tutorías}

La organización institucional del programa de tutorías ofrece a los estudiantes y profesores una estructura general sobre la cual se desarrollan las actividades. Primeramente, se definen fechas o periodos de los tres momentos de intervención. Este mecanismo es importante porque está acompañado de otros aspectos de organización como es la designación de tiempos y espacios para realizar la atención tutorial, y para evitar conflicto con el horario de clases. Esta primera sesión puede marcar el "inicio" del programa de atención y puede variar en las distintas sedes. En algunos casos los profesores establecen el contacto con los estudiantes y organizan directamente con ellos, y en otros casos -la mayoría de ellos-, se programa una reunión plenaria con todos los estudiantes. En estos casos las jornadas son de todo el día, algunos tutores o autoridades ofrecen algún alimento en esta primera sesión plenaria: "yo lo que hago es que reúno básicamente una información muy sencilla para hacerle preguntas a los estudiantes, pero preguntas que me permitan hacer más bien como una plática con ellos en la primera sesión, y les compro algo como de bienvenida, eso puede ser un pastelillo, porque los pobres están desde las 7 de la mañana hasta la última tutoría del primer día que es a las 6 de la tarde y muchos de ellos luego ni han comido, entonces yo les llevó un pastelillo, el mismo para todos o bien los hago un pequeño obsequio, como souvenir de la tienda UV, como son folders, plumas, algo muy sencillo pero muy significativo." (Mónica, tutora, Región Puerto.)

La primera sesión generalmente tiene un componente informativo, que de acuerdo con los testimonios revisados es una de las funciones más frecuente de la tutoría; proveer de información administrativa, fechas, trámites y otros aspectos normativos de la institución. Posteriormente, se considera también un periodo en el cual se ofrece apoyo para la selección de materias, acción que sería específica al acompañamiento y evaluación de la trayectoria estudiantil. En la mayoría de las ocasiones esta sesión es individual o en pequeños grupos; se realizan actividades preparativas a la toma de materias. Algunos anticipan la planeación considerando que algunas materias pueden saturarse o no ser ofertadas y por ello contemplan alternativas.

El cierre de la tutoría implica al tutor la elaboración de informes finales. Algunos profesores comentan que esta última sesión ya no es relevante para el estudiante ya que las decisiones y ayudas, que se concentran de manera importante en la toma de materias y la regularización de su situación al inicio de semestre, ya han sido dadas. Para la mayoría de los tutores los reportes son importantes por su consecuencia administrativa ya que su finalización les permite el reconocimiento y puntaje para los programas de estímulos. No se encuentra evidencia específica de que estos reportes tienen una función en la evaluación institucional.

Este es el esquema básico de atención donde la institución organiza espacios y orienta las funciones básicas de la tutoría. Sin embargo, la actividad de tutoría, tal como la realizan los profesores que participaron en los GF, excede los espacios, periodos y tiempo de dedicación considerados institucionalmente. Todos los tutores coinciden en que la tutoría exige otras interacciones como sesiones individuales, atención telefónica, comunicación por redes sociales, interacciones en pasillos, entre otras. Tutores y tutorados atribuyen el éxito de la tutoría al tiempo y dedicación personal del tutor: "hay cierto problema de parte de la organización, aquí pasa que cuando vamos a empezar a ser tutores que nos asignan a los tutorados no nos indican qué es exactamente, cuál es la labor del tutor, entonces hay muchos maestros que se dedican nada más al tema que nos indican el día de la sesión, por factores de tiempo también y son de asignatura y son de tiempo completo pero el hecho es que no nos indican exactamente esa labor completa, íntegra; entonces lo hacemos creo yo, que lo hacemos quienes estamos comprometidos con los estudiantes, a quién nos gusta tener esa empatía y a quién nos gusta ayudarlos (...)" (Viridiana, tutora, Región Puerto).

Confianza y dinámica de las tutorías

Algunos tutores se involucran en problemas extra-académicos de sus tutorados porque consideran que sirve como estrategia para el desarrollo de la confianza: "me ha tocado lo que decía el maestro Rodrigo, esa parte de hablar con ellos cuestiones que tienen en casa, cuestiones que tienen en la pareja, me ha tocado niñas que se embarazan que no saben qué hacer, que se acercan más a esa parte de decir, bueno no, eres un 
maestro amigable al que le puedo contar las situaciones que tengo, y eso a mí me ha servido mucho porque genera empatía con el estudiantes y a su vez esto hace que podamos tener una relación más cercana y no nos veamos así con que, tú eres el estudiantes, yo soy el maestro y solo tenemos esa interacción" (Mariela, tutora, Región Centro), cómo se ha visto también en la figura 1, los tópicos personales y emocionales son frecuentes, y así como no todos los profesores advierten la necesidad de una atención especializada, incluso lo utilizan como un elemento para que el estudiante genere interés en la tutoría.

En otros casos, los tutores detectan problemas o intereses de los estudiantes que exceden sus atributos y ayudan a canalizar al estudiante para que reciba atención y sin embargo mantienen en juego un elemento de implicación personal, una tutora dice: "(...) me sienten como su amiga, ellos pueden platicarme algún problema ya sea familiar, ya sea económico, o social, o algo académico. Cuando es académico pues obvio que rápidamente lo canalizo, pero cuando es algo personal yo trato de ser muy sutil para que no pierda la confianza en mí, pero sí le doy mi punto de vista, hasta dónde me es posible, pues por mi experiencia soy madre entonces yo siempre pienso en ellos como si fueran mis hijos, mis hijos académicos no los veo como estudiantes, pero siempre dejo que la última decisión la tomen ellos, o sea no me impongo." (Mónica, tutora, Región Puerto).

Algunos tutores consideran que la confianza se gana cuando el estudiante ve resuelto el problema en el que intervinieron (Drake, 2011). En otros casos, la confianza se va construyendo a partir de conversaciones informales sobre temas personales de interés del estudiante (White y Schulenberg, 2012). Esto les permite identificar la necesidad de apoyo y la canalización del estudiante. Otro elemento para desarrollar la confianza son los gestos de amabilidad y atención. Algunas estrategias son las sesiones individuales y las preguntas directas sobre cómo están, o cómo se sienten. Lo anterior es destacado también por los estudiantes: "Me hace ver que siente interés por mí y esa confianza me hace preguntarle sobre más información, y de las inquietudes que yo tengo respecto a las tutorías o en la carrera." (Rubén, estudiante, Región Sur).

Algunos estudiantes relacionan la confianza o la falta de ella por el tipo de reacción del profesor, cuando éste es comprensivo o crítico con sus acciones. Así el "regaño" puede ser valorado positivamente por los estudiantes cuando ellos consideran que se origina en un interés personal del tutor, o el regaño como algo negativo, asociado al juicio y desaprobación del tutor: "No tener ese miedo. Sí he tenido compañeros que no quieren ir a ver a sus tutores porque sienten que los van a regañar. En mi caso no porque mi tutor es accesible, tiene buen trato contigo, hace sentir esa confianza de cuéntame tus problemas, si vas a reprobar una materia dime. No pasa nada, vamos a ver cómo lo solucionamos". (Andrés, estudiante, Región Sur). "Más bien, es un ambiente de confianza que debemos de tener. Porque con mi tutora tenemos una charla, platicamos con ella. No cuesta hablar con ella, sientes un ambiente agradable. En cambio, hay otros que son serios y no dan la confianza de explicar tus dudas. Depende del ambiente." (María, estudiante, Región Sur).

\section{La carga de trabajo}

El número de tutorados atendidos, según lo reportado por los participantes en el grupo focal va de 17 estudiantes hasta 53 lo que en promedio se puede expresar en la atención a 31 estudiantes por profesor. El reglamento institucional de tutorías establece un máximo de 30 tutorados por profesor sin establecer un mínimo. Resulta de interés la comparación con el promedio general por las áreas el cual va de 13 a 17 tutorados por tutor. Algunos profesores argumentan que el número superior de tutorados es resultado de la falta de atención por parte de otros profesores y algunos profesores se hacen receptores de estudiantes que solicitan su cambio de tutor cuando no existen otros disponibles, así que estos profesores absorben la demanda.

La mayoría de los profesores opina que el trabajo de tutoría es más fácil entre menos estudiantes tengan asignados. Presentamos las explicaciones expresadas en algunos GF: "debería haber un límite (...) porque, por decirle, de mis 53 tutorados 25 deben, si no mal recuerdo son doble carrera, entonces ya tenemos un problema ahí. Los tiempos destinados, pues bueno yo tuve que utilizar herramientas tecnológicas (...) mis tres horas en sabatino no me alcanzan, ni siquiera estuvieran informados de nada, si simplemente llegara yo a darles una tutoría de una hora tres veces y el reglamento de tutorías yo se los hago llegar, pero pues realmente los chicos no lo toman en cuenta. O sea, como simplemente yo [estudiante] aquí pues vengo la escucho, me ayuda, me resuelve, pero no es obligatoria para mí la tutoría. Entonces eso es una cosa muy negativa, y que otra cosa, pues creo que sí puedo decir otra cosa negativa realmente desconozco si tienen el reglamento de normatividad, para capacitación para el tutor, yo cuando empecé como tutor no sabía absolutamente nada" (Iraís, Región Centro).

En otro GF se compartió: "yo sí tengo un problema con mis tiempos, porque igual, creo que soy el que menos tiene, pero siento que tengo muchos, veintitantos. Nos dan un día para las tutorías, de igual manera como dice el maestro (menciona nombre), se suspenden las clases ese día, pero, o sea, yo les dedico media hora 
a cada chico y pues ahí estoy mis ocho horas en la facultad, atendiendo chicos. A veces ni tiempo de ir a comer, y no me alcanza el tiempo. Algunos vienen un día antes o un día después, y les doy preferencia a los chicos que no son de aquí. Tengo tutorados que son de Coatepec o de un poquito más allá, que me dicen oiga maestro, ese día no hay que venir a clases y nada más venir para hablar veinte, media hora con usted... Entiendo que es importante, pero la verdad es que no me da económicamente y mis tiempos, venir desde Coatepec hasta acá ese día nada más a la tutoría, entonces con ellos les digo, bueno un día antes que estés aquí en la escuela, cuando salgas de tus clases me pasas a ver, llevamos a cabo la sesión sin problema o un día después, entonces sí, con algunos, principalmente los que no son de aquí de Xalapa, sí" (Fernando, tutor, Región Centro).

En un GF más se comentó "siempre he sido una persona que me exijo mucho y a veces yo considero que me falta mucho como tutora porque a veces siento que no tengo los tiempos. Como yo lo le decía al principio yo siempre le digo a mi coordinadora de tutorías, por ejemplo, ahorita en enero me ingresaron varios y me dice 'te asigno otros tutorados' y yo 'ino! así déjame hasta agosto, que entren los nuevos y ya me vuelves asignar tutorados, pero ahorita con los 18 que tengo estoy bien'. Porque a veces siento que no tengo el tiempo de atenderlos como uno debiera." (Iraís, tutora, Región Centro).

\section{DISCUSIÓN FINAL}

Este estudio se propuso documentar las dinámicas que desarrollan los tutores con el mayor puntaje en el instrumento de evaluación institucional en una universidad mexicana. En los resultados se hizo evidente que el las menciones y representaciones de tutores y estudiantes reconoce a la tutoría como una acción para apoyo del trayecto académico del tutorado, además de otros procesos académicos e institucionales. El análisis de las narraciones de tutores y tutorados revelan que estas acciones que pretenden estar enfocadas al trayecto académico se orientan a dar solución de problemas de origen administrativo.

La práctica de la tutoría, considerando las conceptualizaciones de tutores, tutorados y las acciones que ellos reportan en los grupos focales, dibuja un contexto institucional que obliga a una acción remedial y de emergencia constante, limitando con ello el desarrollo de acciones académicas. Este sería el caso de la propuesta curricular de la institución que en la práctica no tiene un enfoque realmente flexible pues introduce constantes restricciones y riesgos a la continuidad. Muchas de las acciones de las tutorías son anticiparse 0 solucionar estos problemas que la misma institución genera. Considerado esto, se puede argumentar que el Sistema Integral de Tutorías no es un componente integral en la formación académica del tutorado, sino un elemento extracurricular que, en los casos estudiados, ofrece ayuda y soluciones a muchos de los problemas administrativos y de gestión institucional.

Las descripciones permitieron observar que existen otros elementos que son parte de la práctica de la acción tutorial que no están considerados en las normativas y lenguajes institucionales. Los más representativos, porque confluyen aspectos de la práctica, organización y cultura institucional, son el tiempo de trabajo realizado para la atención de la tutoría que excede lo considerado en la lógica institucional. Otro ejemplo es la dinámica de la interacción tutorial, que se organiza en torno a la urgencia de las interacciones comunicativas o para resolver los problemas que originan los mismos procesos institucionales que introduce tensiones en las gestión y desarrollo de las tutorías. Todo ello resulta en la alteración de las funciones de la tutoría y las responsabilidades del tutor quien incorpora a sus roles otras acciones y responsabilidades, como gestionar de manera directa problemas administrativos.

El éxito de la tutoría en el caso estudiado, depende de manera importante de un trabajo que se realiza en tiempo adicional y que exige un compromiso personal del tutor que supone riesgos éticos y laborales al buscar apoyar al estudiante en su formación. La experiencia del tutor en el manejo de los problemas administrativos y conocimiento de la cultura institucional y las relaciones con la administración, son importantes para encontrar la solución a problemas o para la canalización de los estudiantes a otras instancias. Muchos de los tutores reconocen que los sistemas de información institucional pueden ofrecer ayuda importante en el manejo de los expedientes de los estudiantes, pero resultan, en la gran mayoría de los casos, ineficaces para la comunicación con el estudiante y muy limitados en la planificación de los trayectos formativos.

Es importante que la institución replantee teóricamente la tutoría considerando las prácticas actuales y su contexto, así como la toma de medidas para mitigar los problemas que genera la operación de un currículum que en la práctica pone en riesgo a los estudiantes. Aunque el trabajo de los tutores muestra un gran compromiso personal, es de alta relevancia promover una profesionalización de la tutoría guiada por un eje académico. Parece ser necesaria la construcción de una cultura institucional académica, que también ayude al estudiante a comprender su responsabilidad personal y su relación académica con el tutor. Tutores y tutorados muestran frecuentemente estrategias de relación personal más que académica. 
Como comunidad universitaria se hace importante abrir otros espacios para la expresión y el apoyo a otros aspectos de la vida, como puede ser lo emocional, la ansiedad y otros problemas; de esta manera el tutor puede ampliar sus estrategias de canalización y la comunidad reducir la presión sobre los tutores para atender este tipo de problemas. El departamento de tutorías debe considerar nuevos soportes normativos que coincidan con los rubros que se evalúan de la práctica tutorial, que acoten los ejes temáticos sobre los que se debe trabajar, que (dadas las condiciones presentadas por la pandemia) consideren la implementación de un modelo de atención híbrido dentro del marco de los soportes institucionales para no verse en necesidad de usar medios personales; además, es importante contemplar consideraciones éticas y psicopedagógicas para cuidar el proceso y los resultados de la interacción tutorial.

Se hace necesario, a la luz de las prácticas descritas, plantear preguntas más amplias sobre los modelos de tutoría de las universidades. En el caso revisado, la gestión y organización de la tutoría no sólo está enmarcada en el límite normativo sino también presupuestal, las horas de las que dispone la institución juegan un papel importante en limitar formalmente el tiempo de atención y esta circunstancia queda en tensión y contradicción con un modelo impulsado durante los últimos veinte años.

En un estudio de Romo (2004) para conocer la implementación de los programas institucionales de tutoría mostró que el $63.4 \%$ de las instituciones del país optaron por el modelo propuesto por ANUIES, el $12.2 \%$ un modelo que recuperaba elementos de ANUIES y lo modifica con otros elementos propuestos por propia universidad, quedaba un $24.4 \%$ que optaba por un modelo original. Esto significa que la mayoría de las universidades del país impulsaron un mismo modelo, en un mismo contexto de programas de evaluación, acreditación y convocatorias que orientan las acciones por medio de financiamientos por objetivos predefinidos. Es posible que nuevos estudios, similares a este, podrían servir para construir progresivamente una evaluación de los efectos transformadores de esta política en particular y develar nuevos problemas y sobre todo nuevas aproximaciones a la transformación de las universidades.

\section{CONCLUSIONES}

De acuerdo al trabajo presentado y a los resultados obtenidos, se pueden plantear las siguientes conclusiones principales: 1) Sobresale que los tutores que participaron cumplan con su tarea excediendo los marcos espaciales y temporales de sus funciones, 2) No es loable que, en atención a las necesidades estudiantiles y como respuesta a los problemas que se generan en la administración universitaria, los tutores vulneren su privacidad y pasen los marcos normativos para el desempeño de sus funciones, 3) Los tutores enfocan sus esfuerzos en resolver problemas que crea la propia gestión institucional, 4) los tutores pasan mucho tiempo en funciones de información, mismas que puede ser brindadas desde plataformas claras, bien organizadas y accesibles para los estudiantes, 5) a la institución le corresponde crear vías claras y efectivas para la comunicación tutor-tutorado, que no expongan a los involucrados, 6) es necesario hacer los ajustes correspondientes para que el conocimiento y experiencia de los tutores sea aprovechado para guiar el sentido y significado del currículo universitario, en lugar de usarlo en funciones de corte administrativo, 7) La práctica tutoral descrita, a pesar del reconocimiento de la institución por medio de sus evaluaciones, del reconocimiento y valoración de los estudiantes a sus tutores, y del esfuerzo personal de los profesores, no puede ser considerada una práctica deseable, innovadora o una buena práctica que pueda ser transferida a otras instituciones.

\section{REFERENCIAS}

Alonso, G.S., Rodríguez, G.A.M., y Cáceres, R.M.P., Análisis de la acción tutorial y su incidencia en el desarrollo integral del alumnado. El caso de la Universidad de Castilla La Mancha, España, http://dx.doi.org/10.4067/S0718-

50062018000300063, Form. Univ., 11(3) 63-72 (2018)

Amador, P., y Amador, J., Academic advising via Facebook: examining student help seeking, http://doi: 10.1002/abc.20082, The Internet and Higher Ed., 21, 9-16 (2014)

Aristimuño, A., y Parodi, J. P., Un caso real de combate al fracaso en la educación pública: una cuestión de acompañamiento, liderazgo y cultura organizacional, https://doi.org/10.15366/reice2017.15.4.008, REICE, Rev. Ibero. sobre Calidad, Eficacia y Cambio en Educ., 15(4), 141-157 (2017)

Baldwing, R., y Krostseng, M., Incentives in the academy: Issues and options, Incentives for faculty vitality. DOI: 10.1002/he.36919855103, New Directions for Higher Ed., 51, 50-20, (1985)

Barron, T.M.C., y Diaz B.F., Curriculum management and the role of curriculum actors, transnational curriculum, https://doi.org/10.14288/tci.v13i2.188285, Transnational Curriculum Inquiry, 13 (2), 13-33 (2016)

Berg, L.B., Qualitative research methods for the social sciences, 4th ed., 1-162, Allyn and Bacon, Boston, USA (2001)

Bravo, A.A., Faúndez, C.A., y otros dos autores, Formación de estudiantes tutores: un apoyo fundamental para potenciar el desarrollo de prácticas de física, http://dx.doi.org/10.4067/S0718-50062019000200063, Form. Univ., 12(2), 63-72 (2019) 
Caldera, M.J.F., Carranza, A.M.R., y otros dos autores, Actitudes de los estudiantes universitarios ante la tutoría: diseño de una escala de medición., Rev. de la Educ. Sup., 44(173), 103-124 (2015)

Drake, J.K., The role of academic advising in student retention and persistence, http://doi.org/10.1002/abc.20062, About Campus, 16(3), 8-12 (2011)

Fresan, O.M., y Romo, L.A., Programas institucionales de tutorías: una propuesta de la ANUIES para su organización y funcionamiento en las instituciones de educación superior., 3를. Ed., 1-137, ANUIES, México (2011)

Guzmán, J.C., Las buenas prácticas de la enseñanza de los profesores de educación superior, https://doi.org/10.15366/reice2018.16.2.008, Rev. Ibero. sobre Calidad, Eficacia y Cambio en Educ., 16 (2), $133-149$ (2018)

Gordon, E.E., Morgan, R.R., O'Malley, C.J., y Ponticell, J., The Tutoring Revolution. Applying Research for Best Practices, Policy Implications, and Student Achievement. New York: Rowman y Littlefield Education, (2007)

Harrison, E., What constitutes good academic advising nursing students' perceptions of academic advising, http://doi.org/10.3928/01484834-20090615-02, J. of Nursing Ed., 48(7), 361-366 (2009)

He, Y., Hutson, B.L., Bloom, J. L., y Cuevas, A. P., Advisor beliefs, practices, and perceptions of Well-Being: development of an advisor self-evaluation instrument, http://doi.org/10.12930/NACADA-18-02, NACADA J., 40(1), 23-35 (2020)

Holland, C., Westwood, y Naveen, H., Underestimating the relationship between academic advising and attainment: a case study in practice, https://doi.org/10.3389/feduc.2020.00145, Front. Ed., 5 (145), 1-11 (2020)

Kamberelis, G., y Dimitriadis, G., Focus groups: contingent articulations of pedagogy, politics, and inquiry, in The SAGE Handbook of Qualitative Research by N. K. Denzin, N. K. and Lincoln, Y. S., 545-561, Sage Publications Inc., Vol. 4, Los Angeles, USA (2011)

Martinez, E., y Elue, C., Academic advising and the community College Baccalaureate: implications for research, policy, and practice, http://doi.org/10.12930/NACADA-18-16, NACADA J., 40(1), 110-122 (2020)

Ocampo-Gómez, E., Currículum Flexible: estudiantes universitarios sorteando la conformación de su carga académica semestral, Form. Univ., 14(2), 189-200 (2021)

Ocampo, G.E., Jiménez, G.S., y Palacios, R.L., El Investigador fragmentado: conflictos y tensiones derivados de la diversificación de su carga laboral, http://doi.org/10.22201/iisue.20072872e.2020.30.587, Rev. Ibero. de Educ. Sup., 11 (30), 41-56 (2020)

Rodríguez, G.R., La educación superior en el Siglo XXI. Líneas de desarrollo. Una propuesta de ANUIES. Rev. de la Educ. Sup., 29 (113), 1-8 (2000)

Romo, L.A. La incorporación de los programas de tutoría en las instituciones de educación superior, 1-133, ANUIES, México (2004)

Smith, C., y Allen, J., Does Contact with advisors predict judgments and attitudes consistent with student success? A multi-institutional study, http://doi.org/10.12930/NACADA-13-019, NACADA J., 34(1), 50-63 (2014)

Soria, K., y Bultmann, M., Supporting working-class students in higher education, http://doi.org/10.12930/NACADA-13017, NACADA J., 34(2), 51-62 (2014)

Venegas-Ramos, L., y Gairin-Sallan.J., Aproximación al estado de la acción tutorial en universidades chilenas, https://doi.org/10.22201/iisue.24486167e.2019.167.59002, Perfiles Educ., 42(167), 103-118 (2020)

Veselý, A., Theory and Methodology of Best Practice Research: A critical reviews of the Current State. Central European J. of Public Policy, 5(2), 98-117 (2011)

White, E., y Schulenberg, J., Academic advising: a focus on learning. http://doi.org/10.1002/abc.20082. About Campus, 16(6), 11-17 (2012) 